\title{
Monoamine oxidase and transaminase screening: biotransformation of 2-methyl-6-alkylpiperidines by Neopestalotiopsis sp. CBMAI 2030
}

\author{
Jonas Henrique Costa ${ }^{1}$ - Bruna Zucoloto da $\operatorname{Costa}^{1}$ - Derlene Attili de Angelis ${ }^{2}$. \\ Anita Jocelyne Marsaioli ${ }^{1}$
}

Received: 31 March 2017 /Revised: 5 June 2017 / Accepted: 10 June 2017 / Published online: 28 June 2017

(C) The Author(s) 2017. This article is an open access publication

\begin{abstract}
High-throughput screening detected transaminases (TAs) and monoamine oxidases (MAOs) in fungi by applying a fluorogenic probe. Strains F026, F037, F041, F053, and F057 showed the highest enzymatic conversions $(31,60,30,40$, and $32 \%$, respectively) and where evaluated for their ability to transform piperidines. Strain F053 (Neopestalotiopsis sp. CBMAI 2030) revealed unusual enzymatic activity to deracemize 2-methyl-6-alkylpiperidines. Neopestalotiopsis sp. CBMAI 2030 was capable to convert 2-methyl-6-propylpiperidine, 2methyl-6-butylpiperidine, and 2-methyl-6pentylpiperidine in piperideine with 11,14 , and $24 \%$ conversion, respectively. The activity was enhanced by cultivating the fungus with 2-methyl-6-pentylpiperidine (38\% conversion and $73 \%$ ee).
\end{abstract}

Keywords Chiral amines · Fluorogenic probes ·

High-throughput screening $\cdot$ Monoamine oxidase ·

Piperidines $\cdot$ Transaminase

Electronic supplementary material The online version of this article (doi:10.1007/s00253-017-8389-z) contains supplementary material, which is available to authorized users.

Anita Jocelyne Marsaioli

anita@iqm.unicamp.br

Institute of Chemistry, State University of Campinas-UNICAMP, PO Box 6154, Campinas, SP 13083-970, Brazil

2 Division of Microbial Resources, Chemical, Biological and Agricultural Pluridisciplinary Research Center-CPQBA, State University of Campinas-UNICAMP, Campinas, SP 13148-218, Brazil

\section{Introduction}

Chiral amines are often biologically active and synthetically demanding chiral intermediates with applications in pharmaceutical and agrochemical industries (Koszelewski et al. 2010; Carr et al. 2003). Chiral 2-methyl-6-alkylpiperidine moieties are present in solenopsin alkaloids, which are the main components in Solenopsis ant venom. These compounds usually display an $(2 R, 6 S)$ absolute configuration (Pianaro et al. 2012), and their proposed biosynthetic pathway suggests the participation of transaminases (TAs) and imino reductases (IREDs) in the definition of the chiral centers (Leclercq et al. 1996). Nowadays, these stereo-controlled processes can be reproduced in lab by using the same enzyme families (TAIRED cascade) and diketones as substrates (France et al. 2016). Additionally, a similar cascade can also be performed by monoamine oxidases from Aspergillus niger (MAO-N) and $\omega$-transaminases (TA) (Reilly et al. 2014). These enzymes are cofactor-dependent; TAs depend on pyridoxal 5'-phosphate (PLP) and MAO-N on flavin mononucleotide (FMN). TAs catalyze transamination, transferring amino groups from amines or amino acids to amine acceptors, ketones, or $\alpha$-ketoacids, and are relevant to amino acid production in microorganisms and animals (Koszelewski et al. 2010; Hwang and Kim 2004). MAOs have been detected in many organisms (Atkin et al. 2008a, b) and are responsible for the oxidative deamination of monoamines, resulting in hydrogen peroxide and imine formation to produce ketones or aldehydes (Atkin et al. 2008a, b).

In microorganisms, these enzymatic activities can be detected by applying high-throughput screening (HTS) assays. Most HTS methodologies detect signals from a fluorogenic or chromogenic probe in 96-well microplates, which reveal that 
the enzymatic reaction occurred (Reymond 2008). Assays detecting fluorescent signals are more sensitive and provide a linear response to the reaction progress without interference of colored products (Reymond 2006).

Here, we used HTS and a fluorogenic probe recently suggested by $\mathrm{Lu}$ et al. (2008) to monitor MAO and/or TA enzymes in fungi available from LaBioChem in house culture collection, UNICAMP. The enzymatic activity of the best strain was validated in the deracemization of 2,6dialkylpiperidines.

\section{Material and methods}

\section{General methods}

Commercially available reagents and solvents were acquired from Sigma-Aldrich, Acros, or Synth, and purified following standard procedures (Perrin et al. 1980) when necessary. Merck silica gel 60 (230-400 mesh ASTM) was used for "flash" column chromatography, and thin-layer chromatography was performed using Merck silica gel $60 \mathrm{~F}_{254}$ on aluminum foils, revealed by $\mathrm{UV}_{254} \mathrm{~nm}$ lamp irradiation. Visualization spray reagents for TLC were either $10 \% \mathrm{w} / v$ phosphomolybdic acid in ethanol or $p$-anisaldehyde, $\mathrm{H}_{2} \mathrm{SO}_{4}$, acetic acid in ethanol $(1: 2: 1: 100 v / v)$, or Dragendorff's solution containing bismuth(III)nitrate $(0.85 \mathrm{~g})$, tartaric acid $(10 \mathrm{~g})$, and potassium iodide $(16 \mathrm{~g})$ in distilled water $(80 \mathrm{~mL}) .{ }^{1} \mathrm{H}$ NMR $(600.17 \mathrm{MHz})$ and ${ }^{13} \mathrm{C} \mathrm{NMR}(150.91 \mathrm{MHz})$ were acquired with a Bruker Avance III $600\left(B_{0}=14.1 \mathrm{~T}\right)$, and ${ }^{1} \mathrm{H}$ NMR (400.13 MHz) and ${ }^{13} \mathrm{C} \mathrm{NMR}(100.63 \mathrm{MHz})$ were acquired with a Bruker Avance III $400\left(B_{0}=9.4 \mathrm{~T}\right)$. Deuterated chloroform $\left(\mathrm{CDCl}_{3} ; 7.23 \mathrm{ppm}\right)$, deuterated methanol $\left(\mathrm{CD}_{3} \mathrm{OD} ; 3.35\right.$ and $4.78 \mathrm{ppm}$ ), and tetramethylsilane (TMS; $0.0 \mathrm{ppm}$ ) were used as a solvent and internal reference. Chemical shifts were expressed in $\delta(\mathrm{ppm})$ and the coupling constants $(J)$ in Hertz (Hz). The GC-MS analyses were performed in an Agilent 6890 Series chromatograph coupled to a Hewlett-Packard 5973 mass spectrometer with an electron ionization source (EI) operating at $70 \mathrm{eV}$, and equipped with a fused silica capillary column HP 5 -MS $(30 \mathrm{~m} \times 0.25 \mathrm{~mm} \times 0.25 \mu \mathrm{m})$ with $5 \%$ phenylmethylsiloxane. Helium was used as carrier gas $\left(1 \mathrm{~mL} \min ^{-1}\right)$, and the injector temperature was set to $250{ }^{\circ} \mathrm{C}$, detector temperature to $230{ }^{\circ} \mathrm{C}$, and an injection volume of $1.0 \mu \mathrm{L}$ in splitless mode was used. The initial oven temperature was $50{ }^{\circ} \mathrm{C}$, increasing at $20^{\circ} \mathrm{C} \mathrm{min}^{-1}$ to $290{ }^{\circ} \mathrm{C}$. The diastereomeric discrimination of compound $\mathbf{1 1}$ was achieved using an Agilent 6850 chromatograph equipped with a flame ionization detector and a fused silica capillary column Chrompack ${ }^{\circledR}$ with chiral phase Chirasil- $\beta$ - cyclodextrin

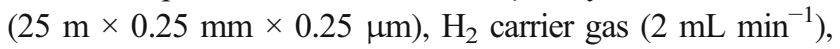
injector at $180^{\circ} \mathrm{C}$, detector at $150{ }^{\circ} \mathrm{C}$, and splitless mode injections of $1.0 \mu \mathrm{L}$. Mass spectrometry with electrospray ionization
(ESI-MS) was performed using a Waters Quattro Micro TM API spectrometer. Samples of compounds $\mathbf{1}$ and $\mathbf{1 d}(10 \mu \mathrm{g} /$ $\mathrm{mL}$ in methanol) were applied by direct infusion using a $50 \mu \mathrm{L} \mathrm{min}{ }^{-1}$, and a $0.1 \mathrm{~mL} \mathrm{~min}^{-1}$ flux of $0.1 \% v / v$ formic acid in methanol was used. Nitrogen was the nebulizing gas, the analyses were performed in the positive mode, and the parameters were as follow: capillary voltage $3 \mathrm{kV}$, cone voltage $25 \mathrm{~V}$, extractor voltage $3 \mathrm{~V}$, RF lens voltage $0.5 \mathrm{~V}$, source temperature $150{ }^{\circ} \mathrm{C}$, desolvation temperature $200{ }^{\circ} \mathrm{C}$, desolving gas flux $800 \mathrm{~L} / \mathrm{h}$, and gas flux at the cone $50 \mathrm{~L} / \mathrm{h}$. Hydrogenations were performed using a Parr 3926 shaker hydrogenation apparatus.

\section{Microorganisms}

Microorganisms (MOs) from our private collection were used in HTS stage, and the hit F053 was identified as Neopestalotiopsis sp. and deposited at CBMAI (Brazilian Collection of Microorganisms from the Environment and Industry) under the code name CBMAI 2030. For the HTS assays, the MOs were inoculated on Petri dishes containing malt extract agar (MEA) culture medium and incubated for $72 \mathrm{~h}$ at $30^{\circ} \mathrm{C}$. The cells were suspended in $20 \mathrm{mM}$ borate buffer $\mathrm{pH} 7.4$ to a final concentration of $1 \mathrm{mg} \mathrm{mL}^{-1}$.

For the biotransformations, MOs were transferred to an Erlenmeyer flask $(500 \mathrm{~mL})$ containing $200 \mathrm{~mL}$ of malt extract (ME) culture medium and incubated at $30^{\circ} \mathrm{C}$ and $200 \mathrm{rpm}$ for $48 \mathrm{~h}$. The cells were harvested by filtration under vacuum and used direct in the assays.

\section{HTS assays}

Screening with whole cells were performed using 7-(3aminopropoxy)coumarin (probe 1) as fluorogenic substrate and following a previously optimized protocol described by Bicalho et al. (2004). The HTS assays were developed in 96well polypropylene microtiter plates in quadruplicate, and reaction controls in duplicate.

Assay (A): $10 \mu \mathrm{L}$ of $2 \mathrm{mM}$ probe 1 solution in water:acetonitrile $(1: 1 v / v), 80 \mu \mathrm{L}$ of $5.0 \mathrm{mg} \mathrm{mL}^{-1}$ BSA in $20 \mathrm{mM}$ borate buffer $\mathrm{pH} 7.4,10 \mu \mathrm{L}$ of $20 \mathrm{mM}$ borate buffer $\mathrm{pH} 7.4$, and $100 \mu \mathrm{L}$ of $1.0 \mathrm{mg} \mathrm{mL}^{-1}$ cell suspension in $20 \mathrm{mM}$ borate buffer $\mathrm{pH} 7.4$.

Negative control (NC): $10 \mu \mathrm{L}$ of $2 \mathrm{mM}$ probe 1 solution in water:acetonitrile $(1: 1 v / v), 80 \mu \mathrm{L}$ of $5.0 \mathrm{mg} \mathrm{mL}^{-1}$

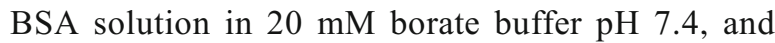
$110 \mu \mathrm{L}$ of $20 \mathrm{mM}$ borate buffer $\mathrm{pH}$ 7.4.

Positive control (PC): $10 \mu \mathrm{L}$ of $2 \mathrm{mM}$ umbelliferone solution in water:acetonitrile $(1: 1 v / v), 80 \mu \mathrm{L}$ of $5.0 \mathrm{mg} \mathrm{mL}^{-1}$ BSA solution in $20 \mathrm{mM}$ borate buffer

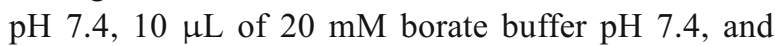
$100 \mu \mathrm{L}$ of $1.0 \mathrm{mg} \mathrm{mL}^{-1}$ cell suspension in $20 \mathrm{mM}$ borate buffer $\mathrm{pH}$ 7.4. 
The microtiter plates were incubated at $30^{\circ} \mathrm{C}$ and $200 \mathrm{rpm}$. The fluorescent signal was monitored using a PerkinElmer EnSpire microtiter plate reader at 0, 24, 48, 72, and $96 \mathrm{~h}$ (excitation wavelength $\lambda_{\mathrm{ex}}=360 \mathrm{~nm}$ and emission wavelength $\left.\lambda_{\mathrm{em}}=460 \mathrm{~nm}\right)$.

The results were expressed as percentage of conversion $(\%)$ applying Eq. 1. All results were averaged and conversion values are estimated, taking the positive control as $100 \%$.

$\%=\frac{(A-N C)}{P C} \times 100$

\section{Biotransformation reactions with 2-methyl-6-alkylpiperidines}

To an Erlenmeyer flask $(50 \mathrm{~mL})$ containing $1 \mathrm{~g}$ of wet cells in $20 \mathrm{~mL}$ of $100 \mathrm{mM}$ Sørensen's phosphate buffer $\mathrm{pH} 7.0$ (Sørensen 1909), compounds 6, 7, or 8 (10 mg) was added. The resulting mixture was incubated at $200 \mathrm{rpm}$ and $30^{\circ} \mathrm{C}$. Biotransformation reactions and negative controls were monitored as follow: 1-mL aliquots were saturated with $\mathrm{NaCl}$, basified with $5.0 \mathrm{M} \mathrm{NaOH}(100 \mu \mathrm{L})$, extracted with ethyl acetate $(2 \times 0.5 \mathrm{~mL})$, and centrifuged at $14,000 \mathrm{rpm}$; the organic layers were combined and analyzed by GC-MS, adding benzophenone $\left(0.1 \mathrm{mg} \mathrm{mL}^{-1}\right)$ as internal standard.

\section{Evolution experiments of Neopestalotiopsis sp. CBMAI 2030}

Erlenmeyer flasks (500 $\mathrm{mL})$ containing compound 8 (10 mg), ME culture medium $(200 \mathrm{~mL})$, and Neopestalotiopsis sp. CBMAI 2030 cells were incubated at $200 \mathrm{rpm}$ and $30^{\circ} \mathrm{C}$ for $48 \mathrm{~h}$. The cells were filtered, washed with $100 \mathrm{mM}$ Sørensen buffer $\mathrm{pH}$ 7.0, and added to the biotransformation reactions. After 15 days, the cells were harvested and added to a new ME culture medium containing compound $\mathbf{8}(10 \mathrm{mg})$. This procedure was repeated three times.

\section{Synthetic procedures}

\section{Tert-butyl-3-chloropropylcarbamate (1c)}

Triethylamine $(1.67 \mathrm{~mL}, 12 \mathrm{mmol})$ was added dropwise to a solution of 3-chloropropylamine (1a, $1.30 \mathrm{~g}, 10 \mathrm{mmol})$ in dichloromethane $(4.5 \mathrm{~mL})$ in a two-neck round-bottom flask. Then, a di-tert-butyldicarbonate (1b) $(2.18 \mathrm{~g}, 10 \mathrm{mmol})$ solution in dichloromethane $(4.5 \mathrm{~mL})$ was added dropwise to the reaction mixture and stirred at room temperature for $18 \mathrm{~h}$. The reaction was quenched by addition of dichloromethane $(10 \mathrm{~mL})$, and the organic phase was washed with $1 \mathrm{M} \mathrm{HCl}(1 \times 10 \mathrm{~mL})$, water $(2 \times 5 \mathrm{~mL}), \mathrm{NaHCO}_{3}$ saturated solution $(1 \times 10 \mathrm{~mL})$, and brine $(1 \times 10 \mathrm{~mL})$. The organic layer was dried over anhydrous
$\mathrm{MgSO}_{4}$ and the solvent was evaporated under reduced pressure. Compound $1 \mathbf{c}$ was obtained as an oily residue $(1.60 \mathrm{~g})$ in $83 \%$ yield. No further purification step was necessary.

M.W.: $193.6 \mathrm{~g} \mathrm{~mol}^{-1}\left(\mathrm{C}_{8} \mathrm{H}_{16} \mathrm{ClNO}_{2}\right) .{ }^{\mathbf{1}} \mathbf{H}$ NMR $\left(400.18 \mathrm{MHz}, \mathrm{CDCl}_{3}, \delta_{\mathrm{TMS}} 0.00\right) \delta 3.59(2 \mathrm{H}, \mathrm{t}, J=6 \mathrm{~Hz}$, $\mathrm{H}-1), 3.28(2 \mathrm{H}, \mathrm{q}, J=6 \mathrm{~Hz}, \mathrm{H}-3), 1.97$ (2H, quint, $J=6 \mathrm{~Hz}$, H-2), 1.44 (9H, s, H-6, H-7, H-8). ${ }^{13}$ C NMR (100.63 MHz, $\mathrm{CDCl}_{3}, \delta_{\mathrm{CDCl} 3}$ 77.0): $\delta 155.9(\mathrm{C}, \mathrm{C}-4), 79.4(\mathrm{C}, \mathrm{C}-5), 42.3$ $\left(\mathrm{CH}_{2}, \mathrm{C}-1\right), 37.9\left(\mathrm{CH}_{2}, \mathrm{C}-3\right), 32.6\left(\mathrm{CH}_{2}, \mathrm{C}-2\right), 28.4\left(\mathrm{CH}_{3}\right.$, C-6, C-7, C-8). EI-MS (70 eV) $\mathrm{m} / \mathrm{z}(\%): 193\left(\mathbf{M}^{+*}\right.$, not present), 140 (14), 138 (41), 137 (4), 134 (5), 94 (5), 93 (4), 59 (48), 58 (7), 57 (100), 56 (11). TLC (ethyl acetate, phosphomolybdic acid stain solution) $\mathrm{R}_{f}=0.6$. Spectra: See Figs. S1, S2, and S3 in Online Resource 1.

Tert-butyl (3-((2-oxo-2H-chromen-7-yloxy)propyl)carbamate (1d)

Umbelliferone $(0.325 \mathrm{~g}, 2 \mathrm{mmol})$ and acetone $(10 \mathrm{~mL})$ were added to a two-neck round-bottom flask under nitrogen atmosphere. The mixture was cooled to $0{ }^{\circ} \mathrm{C}$ and $1 \mathrm{c}(0.956 \mathrm{~g}$, $5 \mathrm{mmol})$; potassium carbonate $(0.47 \mathrm{~g}, 3.5 \mathrm{mmol})$ and sodium iodide $(0.45 \mathrm{~g}, 3.0 \mathrm{mmol})$ were added. The reaction was kept under reflux for $18 \mathrm{~h}$. The solvent was evaporated under reduced pressure and the crude residue was purified by silica gel column chromatography eluted with hexane:ethyl acetate $(2: 1 v / v)$ to produce $0.57 \mathrm{~g}$ of solid $\mathbf{1 d}$, in $89 \%$ yield.

M.W.: $319.1 \mathrm{~g} \mathrm{~mol}^{-1}\left(\mathrm{C}_{17} \mathrm{H}_{21} \mathrm{NO}_{5}\right)$. ${ }^{\mathbf{1}} \mathbf{H} \mathbf{~ N M R}$ $\left(400.18 \mathrm{MHz}, \mathrm{CD}_{3} \mathrm{OD}, \delta_{\mathrm{CD} 3 \mathrm{OD}} 4.87 \mathrm{ppm}\right): \delta 7.86(1 \mathrm{H}, \mathrm{d}$, $J=9 \mathrm{~Hz}, \mathrm{H}-3), 7.51(1 \mathrm{H}, \mathrm{d}, J=9 \mathrm{~Hz}, \mathrm{H}-9), 6.92(1 \mathrm{H}, \mathrm{dd}$, $J=9$ e $2 \mathrm{~Hz}, \mathrm{H}-8), 6.88(1 \mathrm{H}, \mathrm{d}, J=2 \mathrm{~Hz}, \mathrm{H}-6), 6.23(1 \mathrm{H}, \mathrm{d}$, $J=9 \mathrm{~Hz}, \mathrm{H}-2), 4.10(2 \mathrm{H}, \mathrm{t}, J=6 \mathrm{~Hz}, \mathrm{H}-10), 3.24(2 \mathrm{H}, \mathrm{q}$, $J=6 \mathrm{~Hz}, \mathrm{H}-12), 1.97(2 \mathrm{H}$, quint, $J=6 \mathrm{~Hz}, \mathrm{H}-11), 1.42(9 \mathrm{H}, \mathrm{s}$, $\mathrm{H}-15, \mathrm{H}-16, \mathrm{H}-17) .{ }^{13} \mathbf{C}$ NMR $\left(100.63 \mathrm{MHz}, \mathrm{CD}_{3} \mathrm{OD}, \delta_{\mathrm{CD} 3 \mathrm{OD}}\right.$ 49,2 ppm): $\delta 164.1$ (C, C-7), 163.5 (C, C-1), 158.7 (C, C-13), 157.2 (C, C-5), 145.9 (CH, C-3), 130.6 (CH, C-9), $114.4(\mathrm{CH}$, C-8), 114.1 (C, C-4), 113.5 (CH, C-2), 102.4 (CH, C-6), 80.1 (C, C-14), $67.5\left(\mathrm{CH}_{2}, \mathrm{C}-10\right), 38.4\left(\mathrm{CH}_{2}, \mathrm{C}-12\right), 30.7\left(\mathrm{CH}_{2}\right.$, C-11), $28.9\left(\mathrm{CH}_{3}, \mathrm{C}-15, \mathrm{C}-16, \mathrm{C} 17\right) . \mathbf{E S I}^{+} / \mathbf{M S}: 358.1$ $\left(\mathrm{C}_{17} \mathrm{H}_{20} \mathrm{NO}_{5} \mathrm{~K}^{+}\right), 342.1\left(\mathrm{C}_{17} \mathrm{H}_{20} \mathrm{NO}_{5} \mathrm{Na}^{+}\right), 320.1$ $\left(\mathrm{C}_{17} \mathrm{H}_{21} \mathrm{NO}_{5} \mathrm{H}^{+}\right)$. TLC (hexane:ethyl acetate, 1:1 v/v, phosphomolybdic acid stain solution) $\mathrm{R}_{f}=0.4$. Spectra: See Figs. S4, S5, and S6 in Online Resource 1.

\section{7-(3-Aminopropoxy)coumarin (1)}

Compound 1d (160 mg, $0.5 \mathrm{mmol})$, water:trifluoroacetic acid $1: 1 v / v(10 \mathrm{~mL})$, dichloromethane $(10 \mathrm{~mL})$, and triisopropylsilane $(20 \mu \mathrm{L})$ were added to a two-neck round-bottom flask. The mixture was stirred at room temperature for $30 \mathrm{~min}$. The crude product was purified using a Sep-Pak column $\left(\mathrm{C} 18,3 \mathrm{~cm}^{3}\right.$, Waters) and eluted with methanol. Compound $\mathbf{1}$ was obtained as a whitish solid in quantitative yield $(0.125 \mathrm{~g})$. 
Fig. 1 Fluorogenic assay to detect monoamine oxidases (MAOs) and transaminases (TAs). BSA bovine serum albumin

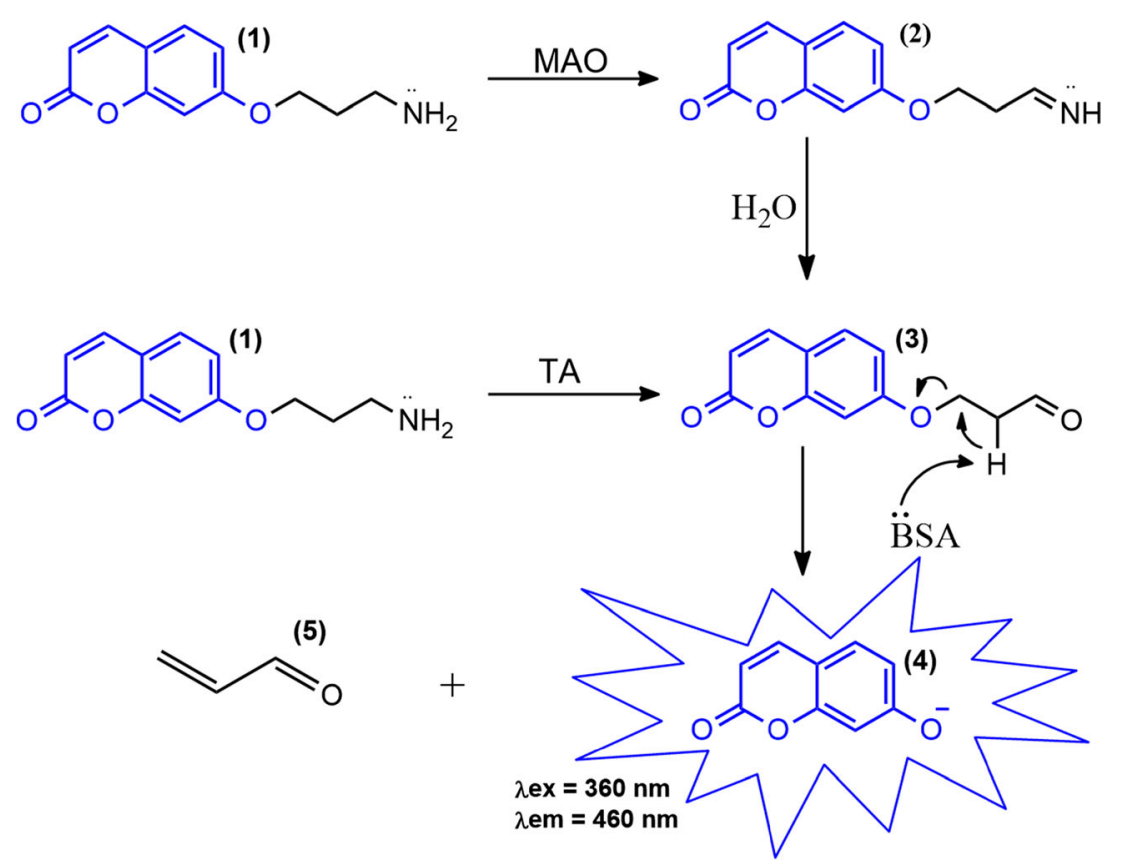

M.W.: $219.2 \mathrm{~g} \mathrm{~mol}^{-1}\left(\mathrm{C}_{12} \mathrm{H}_{13} \mathrm{NO}_{3}\right) .{ }^{1} \mathbf{H}$ NMR $(600 \mathrm{MHz}$, $\left.\mathrm{CD}_{3} \mathrm{OD}, \delta_{\mathrm{CD} 3 \mathrm{OD}} 4.87 \mathrm{ppm}\right): \delta 7.91(1 \mathrm{H}, \mathrm{d}, J=9 \mathrm{~Hz}, \mathrm{H}-3)$, $7.58(1 \mathrm{H}, \mathrm{d}, J=9 \mathrm{~Hz}, \mathrm{H}-9), 6.98(1 \mathrm{H}, \mathrm{dd}, J=9 \mathrm{e} 2.4 \mathrm{~Hz}, \mathrm{H}-8)$, $6.96(1 \mathrm{H}, \mathrm{d}, J=2.4 \mathrm{~Hz}, \mathrm{H}-6), 6.28(1 \mathrm{H}, \mathrm{d}, \mathrm{J}=9 \mathrm{~Hz}, \mathrm{H}-2), 4.23$ $(2 \mathrm{H}, \mathrm{t}, J=6 \mathrm{~Hz}, \mathrm{H}-10), 3.19$ (2H, q, $J=6 \mathrm{~Hz}, \mathrm{H}-12), 2.20(2 \mathrm{H}$, quint, $J=6 \mathrm{~Hz}, \mathrm{H}-11) .{ }^{13} \mathbf{C}$ NMR $\left(150 \mathrm{MHz}, \mathrm{CD}_{3} \mathrm{OD}, \delta_{\mathrm{CD} 3 \mathrm{OD}}\right.$ 49.2 ppm): $\delta 163.5$ (C, C-7), 163.4 (C, C-1), 157.2 (C, C-5), 145.8 (CH, C-3), 130.7 (CH, C-9), 114.7 (C, C-4), 114.2 (CH, C-8), 113.9 (CH, C-2), $102.6(\mathrm{CH}, \mathrm{C}-6), 67.0\left(\mathrm{CH}_{2}, \mathrm{C}-10\right)$, $38.6\left(\mathrm{CH}_{2}, \mathrm{C}-12\right), \delta 28.3\left(\mathrm{CH}_{2}, \mathrm{C}-11\right) . \mathbf{E S I}^{+} / \mathbf{M S}: 220.3$ $\left(\mathrm{C}_{12} \mathrm{H}_{13} \mathrm{NO}_{3} \mathrm{H}^{+}\right)$. TLC (hexane:ethyl acetate, $1: 1 \mathrm{v} / \mathrm{v}$, phosphomolybdic acid stain solution) $R_{f}=0.2$. Spectra: See Figs. S7, S8, and S9 in Online Resource 1.

\section{2-Methyl-6-alkylpyridine (6b, 7b, and 8b)}

To a stirring solution of 2,6-lutidine (9) $(2 \mathrm{~mL})$ in dry THF $(15 \mathrm{~mL})$, under nitrogen atmosphere and at $0{ }^{\circ} \mathrm{C}$, 1.6 M BuLi in hexane ( $n$-butyl lithium, $13 \mathrm{~mL}$ ) was added slowly. The reaction was maintained at room temperature for $15 \mathrm{~min}$ and then heated to reflux for $15 \mathrm{~min}$. The reaction mixture was cooled to $0{ }^{\circ} \mathrm{C}$, and iodoethane $(1.65 \mathrm{~mL})$, allylbromide $(1.79 \mathrm{~mL})$, or 1-bromobutane $(2 \mathrm{~mL})$ was slowly added. The reaction was stirred for $18 \mathrm{~h}$. Work-up was performed with cold water $(25 \mathrm{~mL})$ and by extraction with ethyl acetate $(2 \times 20 \mathrm{~mL})$. The organic layers were combined and dried over anhydrous $\mathrm{MgSO}_{4}$. The solvent was evaporated and the crude product was purified by silica gel column chromatography (hexane:ethyl acetate, 9:1 v/v) to yield 1.41, 1.65, and $1.70 \mathrm{~g}$ of $\mathbf{6 b}, \mathbf{7 b}$, and $\mathbf{8 b}$, respectively, as yellow oils in 60,64 , and $60 \%$ yield, respectively. 2-methyl-6-propylpyridine (6b) M.W.: $135.1 \mathrm{~g} \mathrm{~mol}^{-1}$ $\left(\mathrm{C}_{9} \mathrm{H}_{13} \mathrm{~N}\right) .{ }^{1} \mathbf{H}$ NMR $\left(600.17 \mathrm{MHz}, \mathrm{CDCl}_{3}, \delta_{\mathrm{TMS}} 0.00\right): \delta$ $7.47(1 \mathrm{H}, \mathrm{t}, J=7.8 \mathrm{~Hz}, \mathrm{H}-4), 6.95(2 \mathrm{H}, \mathrm{t}, J=7.8 \mathrm{~Hz}, \mathrm{H}-3$, H-5), 2.73 (2H, t, $J=7,8 \mathrm{~Hz}, \mathrm{H}-7), 2.53$ (3H, s, H-10), 1.70 (2H, sex, $J=7,8 \mathrm{~Hz}, \mathrm{H}-8), 0.97(3 \mathrm{H}, \mathrm{t}, \mathrm{J}=7,8 \mathrm{~Hz}, \mathrm{H}-9) .{ }^{13} \mathbf{C}$ NMR (150.92 MHz, $\mathrm{CDCl}_{3}, \delta_{\mathrm{CDCl}}$ 77,0): $\delta 161.9$ (C, C-2), 157.9 (C, C-6), 136.6 (CH, C-4), 120.6 (CH, C-3), 119.7 (CH, $\mathrm{C}-5), 40.7\left(\mathrm{CH}_{2}, \mathrm{C}-7\right), 24.7\left(\mathrm{CH}_{3}, \mathrm{C}-10\right), 23.6\left(\mathrm{CH}_{2}, \mathrm{C}-8\right)$, $14.1\left(\mathrm{CH}_{2}, \mathrm{C}-9\right)$. EI/MS (70 eV) $\mathrm{m} / z(\%): 135\left(\mathrm{M}^{*+}, 3\right), 134$ (15), 120 (32), 108 (9), 107 (100), 106 (7), 93 (5), 92 (5), 77 (5), 65 (4), 66 (6). Spectra: See Figs. S10, S11, and S12 in Online Resource 1.

2-methyl-6-(but-3-en-1-yl)pyridine (7b) M.W.: $147.1 \mathrm{~g} \mathrm{~mol}^{-1}\left(\mathrm{C}_{10} \mathrm{H}_{13} \mathrm{~N}\right) .{ }^{1} \mathbf{H}$ NMR $\left(400.18 \mathrm{MHz}, \mathrm{CDCl}_{3}\right.$, $\left.\delta_{\mathrm{TMS}} 0.00\right): \delta 7.47(1 \mathrm{H}, \mathrm{t}, J=7.6 \mathrm{~Hz}, \mathrm{H}-4), 6.95(2 \mathrm{H}, \mathrm{t}$, $J=6.8 \mathrm{~Hz}, \mathrm{H}-3, \mathrm{H}-5), 5.87(1 \mathrm{H}, \mathrm{m}, \mathrm{J}=17.2,10$ e $6.4 \mathrm{~Hz}$, H-9), $5.05(1 \mathrm{H}, \mathrm{d}, J=16.8 \mathrm{~Hz}, \mathrm{H}-10$ trans $), 4.97(1 \mathrm{H}, \mathrm{d}$, $J=10.0 \mathrm{~Hz}, \mathrm{H}-10 \mathrm{cis}), 2.85$ (2H, t, $J=7.6 \mathrm{~Hz}, \mathrm{H}-7), 2.53$ (3H, s, H-11), $2.47(2 \mathrm{H}, \mathrm{q}, J=7.2 \mathrm{~Hz}, \mathrm{H}-8) .{ }^{13} \mathbf{C}$ NMR $\left(100.63 \mathrm{MHz}, \mathrm{CDCl}_{3}, \delta_{\mathrm{CDCl} 3}\right.$ 77,0): $\delta 161.0$ (C, C-2), 157.9 (C, C-6), 138.1 (CH, C-9), 136.7 (CH, C-4), 120.7 (CH, C-3), 119.8 (CH, C-5), 115.1( $\left.\mathrm{CH}_{2}, \mathrm{C}-10\right), 37.9\left(\mathrm{CH}_{2}, \mathrm{C}-7\right), 34.2$ $\left(\mathrm{CH}_{2}, \mathrm{C}-8\right), 24.7\left(\mathrm{CH}_{3}, \mathrm{C}-11\right)$. IE/EM (70 eV) $\mathrm{m} / \mathrm{z}(\%): 147$ $\left(\mathrm{M}^{*+}, 57\right), 146$ (100), 144 (9), 132 (47), 131 (35), 130 (9), 107 (25), 106 (7), 93 (14), 77 (11). Spectra: See Figs. S13, S14, and S15 in Online Resource 1.

2-methyl-6-pentylpyridine (8b) M.W.: $163.2 \mathrm{~g} \mathrm{~mol}^{-1}$ $\left(\mathrm{C}_{11} \mathrm{H}_{17} \mathrm{~N}\right) .{ }^{1} \mathbf{H}$ NMR $\left(400.18 \mathrm{MHz}, \mathrm{CDCl}_{3}, \delta_{\mathrm{TMS}} 0,00\right)$ : $\delta 7.47(1 \mathrm{H}, \mathrm{t}, J=7.6 \mathrm{~Hz}, \mathrm{H}-4), 6.95(2 \mathrm{H}, \mathrm{dd}, J=3.3$ and $7.6 \mathrm{~Hz}, \mathrm{H}-3, \mathrm{H}-5), 2.74(2 \mathrm{H}, \mathrm{t}, J=7.8 \mathrm{~Hz}, \mathrm{H}-7), 2.53$ $(3 \mathrm{H}, \mathrm{s}, \mathrm{H}-12), 1,70(2 \mathrm{H}$, quin, $J=5.3 \mathrm{~Hz}, \mathrm{H}-8), 1.35(4 \mathrm{H}$, m, H-9, H-10), 0.89 (3H, t, J = $6.9 \mathrm{~Hz}, \mathrm{H}-11) .{ }^{13} \mathbf{C}$ NMR 
Table 1 Enzymatic conversion (\%) of fluorogenic probe 1 by fungi

\begin{tabular}{|c|c|c|c|c|}
\hline \multirow[t]{2}{*}{ Identification number } & \multicolumn{4}{|c|}{ Conversion $^{\mathrm{a}}(\%)$} \\
\hline & $24 \mathrm{~h}$ & $48 \mathrm{~h}$ & $72 \mathrm{~h}$ & $96 \mathrm{~h}$ \\
\hline F023 & 19 & 23 & 24 & 11 \\
\hline F024 & 13 & 17 & 19 & 13 \\
\hline F025 & 0 & 0 & 0 & 0 \\
\hline F026 & 18 & 23 & 27 & 31 \\
\hline F027 & 15 & 21 & 23 & 25 \\
\hline F028 & 10 & 15 & 17 & 20 \\
\hline F029 & 13 & 16 & 16 & 20 \\
\hline F030 & 1 & 1 & 2 & 3 \\
\hline F031 & 0.5 & 1 & 1 & 2 \\
\hline F032 & 6 & 6 & 10 & 13 \\
\hline F033 & 0.5 & 1 & 1 & 1 \\
\hline F034 & 2 & 3 & 4 & 5 \\
\hline F035 & 3 & 4 & 6 & 7 \\
\hline F037 & 43 & 60 & 60 & 60 \\
\hline F038 & 2 & 3 & 4 & 5 \\
\hline F039 & 6 & 8 & 9 & 11 \\
\hline F040 & 9 & 12 & 14 & 19 \\
\hline F041 & 9 & 13 & 16 & 30 \\
\hline F042 & 5 & 6 & 9 & 10 \\
\hline F043 & 0 & 1 & 1 & 1 \\
\hline F045 & 12 & 16 & 22 & 25 \\
\hline F046 & 16 & 18 & 19 & 22 \\
\hline F047 & 4 & 5 & 7 & 10 \\
\hline F048 & 0 & 0 & 1 & 2 \\
\hline F049 & 1 & 1 & 2 & 3 \\
\hline F050 & 1 & 2 & 2 & 4 \\
\hline F051 & 1 & 2 & 3 & 3 \\
\hline F052 & 1 & 1 & 2 & 2 \\
\hline F053 & 22 & 29 & 35 & 40 \\
\hline F054 & 1 & 1 & 1 & 1 \\
\hline F055 & 2 & 2 & 3 & 3 \\
\hline F056 & 2 & 4 & 6 & 7 \\
\hline F057 & 17 & 20 & 24 & 32 \\
\hline F058 & 3 & 4 & 5 & 6 \\
\hline F059 & 4 & 7 & 9 & 12 \\
\hline F060 & 1 & 2 & 3 & 4 \\
\hline F062 & 2 & 3 & 4 & 5 \\
\hline F063 & 6 & 14 & 19 & 21 \\
\hline L019 & 0 & 0 & 0 & 1 \\
\hline
\end{tabular}

${ }^{\text {a }}$ Calculated using the Equation 1 presented in the experimental procedure

$\left(100.63 \mathrm{MHz}, \mathrm{CDCl}_{3}, \delta_{\mathrm{CDCl} 3}\right.$ 77.0): $\delta 161.9(\mathrm{C}, \mathrm{C}-2)$, $157.6(\mathrm{C}, \mathrm{C}-6), 136.4(\mathrm{CH}, \mathrm{C}-4), 120.3(\mathrm{CH}, \mathrm{C}-3)$, $119.4(\mathrm{CH}, \mathrm{C}-5), 38.6\left(\mathrm{CH}_{2}, \mathrm{C}-7\right), 31.7\left(\mathrm{CH}_{2}, \mathrm{C}-8\right)$, $29.9\left(\mathrm{CH}_{2}, \mathrm{C}-9\right), 24.5\left(\mathrm{CH}_{3}, \mathrm{C}-12\right), 22.5\left(\mathrm{CH}_{2}, \mathrm{C}-10\right)$, $14.0\left(\mathrm{CH}_{2}, \mathrm{C}-11\right) . \mathbf{E I} / \mathbf{M S}(70 \mathrm{eV}) \mathrm{m} / \mathrm{z}(\%): 163\left(\mathrm{M}^{*+}\right.$, 1), 134 (28), 132 (3), 121 (6), 120 (27), 108 (9), 107

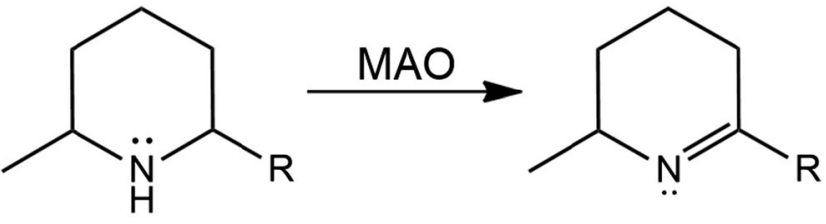

(6) $\mathrm{R}=\left(\mathrm{CH}_{2}\right)_{2} \mathrm{CH}_{3}$

(6a) $\mathrm{R}=\left(\mathrm{CH}_{2}\right)_{2} \mathrm{CH}_{3}$

(7) $\mathrm{R}=\left(\mathrm{CH}_{2}\right)_{3} \mathrm{CH}_{3}$

(7a) $\mathrm{R}=\left(\mathrm{CH}_{2}\right)_{3} \mathrm{CH}_{3}$

(8) $\mathrm{R}=\left(\mathrm{CH}_{2}\right)_{4} \mathrm{CH}_{3}$

(8a) $\mathrm{R}=\left(\mathrm{CH}_{2}\right)_{4} \mathrm{CH}_{3}$

Fig. 2 Biotransformation of 2-methyl-6-alkylpiperidines by MAO

(100), 106 (7), 92 (4), 77 (5), 65 (4). Spectra: See Figs. $\mathrm{S} 16, \mathrm{~S} 17$, and $\mathrm{S} 18$ in Online Resource 1. TLC (hexane:ethyl acetate, $8: 2 \mathrm{v} / \mathrm{v}$, anisaldehyde stain solution) $\mathrm{Rf}=0.6$.

\section{2-Methyl-6-alkylpiperidines (6, 7, and 8)}

Solutions of $\mathbf{6 b}, \mathbf{7 b}$, or $\mathbf{8 b}(0.5 \mathrm{~g})$ in methanol $(8 \mathrm{~mL})$ and glacial acetic acid $(40 \mathrm{~mL})$ with $\mathrm{Pt} / \mathrm{C} 10 \%(100 \mathrm{mg})$ were hydrogenated at 60 bar $\mathrm{H}_{2}$ and $500 \mathrm{rpm}$ for $48 \mathrm{~h}$ using a Parr 3926 shaker hydrogenator. The reaction mixture was filtered over a Celite $545 \mathrm{pad}(2 \mathrm{~g})$ and eluted with methanol $(50 \mathrm{~mL})$. Solvent evaporation yielded the crude product, which was purified by silica gel column chromatography, eluted with methanol, to yield $0.5,0.48$, and $0.5 \mathrm{~g}$ of $\mathbf{6}, 7$, and $\mathbf{8}$, respectively, as yellow oils in 99, 98, and 99\% yield, respectively.

2-methyl-6-propylpiperidine (6) M.W.: $141.2 \mathrm{~g} \mathrm{~mol}^{-1}$ $\left(\mathrm{C}_{9} \mathrm{H}_{19} \mathrm{~N}\right) .{ }^{1} \mathbf{H}$ NMR $\left(600.18 \mathrm{MHz}, \mathrm{CDCl}_{3}, \delta_{\mathrm{TMS}} 0.00\right): \delta$ $3.11(1 \mathrm{H}, \mathrm{m}, \mathrm{H}-2), 2.96(1 \mathrm{H}, \mathrm{s}, \mathrm{H}-6), 1.90-1.25(14 \mathrm{H}, \mathrm{m})$, $0.92(3 \mathrm{H}, \mathrm{t}, J=11 \mathrm{~Hz}, \mathrm{H}-9) .{ }^{13} \mathbf{C}$ NMR $(150.93 \mathrm{MHz}$, $\mathrm{CDCl}_{3}, \delta_{\mathrm{CDCl}}$ 77.0) $\delta 57.2(\mathrm{CH}, \mathrm{C}-2), 53.6(\mathrm{CH}, \mathrm{C}-6), 35.4$ $\left(\mathrm{CH}_{2}, \mathrm{C}-7\right), 30.8\left(\mathrm{CH}_{2}, \mathrm{C}-3\right), 28.0\left(\mathrm{CH}_{2}, \mathrm{C}-5\right), 22.9\left(\mathrm{CH}_{2}\right.$, C-4), $19.2\left(\mathrm{CH}_{3}, \mathrm{C}-10\right), 18.5\left(\mathrm{CH}_{2}, \mathrm{C}-8\right), 13.8\left(\mathrm{CH}_{2}, \mathrm{C}-9\right)$. EI/MS (70 eV) $\mathrm{m} / z(\%) 141\left(\mathrm{M}^{*+}, 2\right), 126(8), 112(3), 99$ (8), 98 (100), 84 (3), 81 (3), 70 (5), 56 (5), 55 (5). Spectra: See Figs. S19, S20, and S21 in Online Resource 1.

2-methyl-6-butylpiperidine (7) M.W.: $155.3 \mathrm{~g} \mathrm{~mol}^{-1}$ $\left(\mathrm{C}_{10} \mathrm{H}_{21} \mathrm{~N}\right) .{ }^{1} \mathbf{H}$ NMR $\left(400.18 \mathrm{MHz}, \mathrm{CDCl}_{3}, \delta_{\mathrm{TMS}} 0.00\right): \delta$ $3.02(1 \mathrm{H}, \mathrm{m}, \mathrm{H}-2), 2.86(1 \mathrm{H}, \mathrm{s}, \mathrm{H}-6), 1.90-1,31(16 \mathrm{H}, \mathrm{m})$, $0,88(3 \mathrm{H}, \mathrm{t}, J=7,2 \mathrm{~Hz}, \mathrm{H}-10) .{ }^{\mathbf{1 3}} \mathbf{C}$ NMR $(100.63 \mathrm{MHz}$, $\left.\mathrm{CDCl}_{3}, \delta_{\mathrm{CDCl} 3} 77.0\right): \delta 57.5(\mathrm{CH}, \mathrm{C}-2), 53.6(\mathrm{CH}, \mathrm{C}-6)$, $33.3\left(\mathrm{CH}_{2}, \mathrm{C}-7\right), 31.4\left(\mathrm{CH}_{2}, \mathrm{C}-3\right), 28.7\left(\mathrm{CH}_{2}, \mathrm{C}-5\right), 27.7$ $\left(\mathrm{CH}_{2}, \mathrm{C}-4\right), 23.3\left(\mathrm{CH}_{2}, \mathrm{C}-8\right), 23.1\left(\mathrm{CH}_{3}, \mathrm{C}-11\right), 22.5\left(\mathrm{CH}_{2}\right.$, C-9), $19.6\left(\mathrm{CH}_{2}, \mathrm{C}-10\right)$. EI/MS (70 eV) $\mathrm{m} / \mathrm{z}(\%) 154\left(\mathrm{M}^{\circ+}, 3\right)$, 140 (7), 112 (3), 99 (7), 98 (100), 84 (3), 81 (3), 70 (5), 56 (5), 55 (5). Spectra: See Figs. S22, S23, and S24 in Online Resource 1.

2-methyl-6-pentylpiperidine (8) M.W.: $169.3 \mathrm{~g} \mathrm{~mol}^{-1}$ $\left(\mathrm{C}_{11} \mathrm{H}_{23} \mathrm{~N}\right) .{ }^{1} \mathbf{H}$ NMR $\left(400.18 \mathrm{MHz}, \mathrm{CDCl}_{3}, \delta_{\text {TMS }} 0,00\right): \delta$ 3.05 (1H, m, H-2), 2.88 (1H, s, H-6), 2.00-1.25 (18H, m), 
Fig. 3 Synthetic route from 2,6lutidine (9) to 2-methyl-6alkylpiperidines. Reagents and conditions: (i) $n$-BuLi, anhydrous THF, $0{ }^{\circ} \mathrm{C}$ to r.t.; (ii) alkyl halide; and (iii) $\mathrm{Pt} / \mathrm{C}(10 \%), 60 \mathrm{bar}_{2}$, $\mathrm{CH}_{3} \mathrm{COOH} / \mathrm{MeOH}(5: 1 v / v)$, r.t., $48 \mathrm{~h}$
I)<smiles>Cc1cccc(C)n1</smiles>

(9)

II)<smiles>Cc1cccc(P)n1</smiles><smiles>Cc1cccc(C)n1</smiles>

(10)
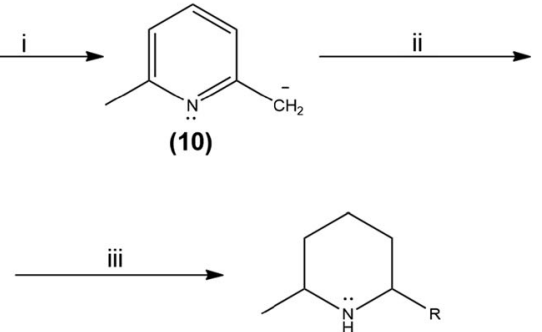

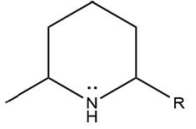

(6) $\mathrm{R}=\left(\mathrm{CH}_{2}\right)_{2} \mathrm{CH}_{3}$

(7) $\mathrm{R}=\left(\mathrm{CH}_{2}\right)_{3} \mathrm{CH}_{3}$

(8) $\mathrm{R}=\left(\mathrm{CH}_{2}\right)_{4} \mathrm{CH}_{3}$

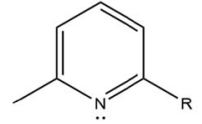

(6b) $\mathrm{R}=\left(\mathrm{CH}_{2}\right)_{2} \mathrm{CH}_{3}$ (7b) $\mathrm{R}=\left(\mathrm{CH}_{2}\right)_{2} \mathrm{CH}=\mathrm{CH}_{2}$ (8b) $\mathrm{R}=\left(\mathrm{CH}_{2}\right)_{4} \mathrm{CH}_{3}$

$0.87(3 \mathrm{H}, \mathrm{t}, J=8 \mathrm{~Hz}, \mathrm{H}-11) .{ }^{13} \mathbf{C}$ NMR $(100.63 \mathrm{MHz}$, $\left.\mathrm{CDCl}_{3}, \delta_{\mathrm{CDCl} 3} 77.0\right): \delta 57.4(\mathrm{CH}, \mathrm{C}-2), 53.4(\mathrm{CH}, \mathrm{C}-6)$, $33.3\left(\mathrm{CH}_{2}, \mathrm{C}-7\right), 31.4\left(\mathrm{CH}_{2}, \mathrm{C}-3\right), 30.8\left(\mathrm{CH}_{2}, \mathrm{C}-5\right)$, $27.9\left(\mathrm{CH}_{2}, \mathrm{C}-4\right), 25.0\left(\mathrm{CH}_{2}, \mathrm{C}-8\right), 23.0\left(\mathrm{CH}_{2}, \mathrm{C}-9\right)$, $22.8\left(\mathrm{CH}_{3}, \mathrm{C}-12\right), 22.5\left(\mathrm{CH}_{2}, \mathrm{C}-10\right), 19.2\left(\mathrm{CH}_{2}\right.$, C-11). EI/MS (70 eV) $\mathrm{m} / \mathrm{z}(\%) 169\left(\mathrm{M}^{\bullet+}, 2\right), 168$ (3), 154 (7), 126 (2), 99 (7), 98 (100), 81 (2), 70 (4), 69 (2), 56 (3), 55 (3). TLC (methanol:chloroform 5:95, Dragendorff stain solution) $\mathrm{RF}=0.5$. Spectra: See Figs. S25, S26, and S27 in Online Resource 1.

\section{2,2,2-Trifluor-1-(2-methyl-6-pentylpiperidine-1-il)ethanone (11)}

Diethyl ether (1 mL) was used to solubilize 2-methyl-6pentylpiperidine $(8)(2 \mathrm{mg})$. Dry pyridine $(0.8 \mathrm{~mL})$ and trifluoroacetic anhydride $(200 \mu \mathrm{L})$ were added slowly, and the reaction was kept at $30{ }^{\circ} \mathrm{C}$ for $30 \mathrm{~min}$. The reaction was quenched by adding ethyl acetate $(4 \mathrm{~mL})$ and an aqueous solution of copper sulfate $(4 \times 4 \mathrm{~mL})$. The organic layer was separated and dried over anhydrous $\mathrm{MgSO}_{4}$. The solvent was evaporated under reduced pressure to yield $\mathbf{1 1}(2.3 \mathrm{mg}, 99 \%)$ as an oily residue.

MM: $265.3 \mathrm{~g} \mathrm{~mol}^{-1}\left(\mathrm{C}_{13} \mathrm{H}_{22} \mathrm{~F}_{3} \mathrm{NO}\right)$. EI/MS (70 eV) $\mathrm{m} / \mathrm{z}$ (\%): $265\left(\mathrm{M}^{*+}, 1\right), 222$ (2), 196 (4), 195 (10), 194 (100), 152

Table 2 Biotransformation of 6,7 , and $\mathbf{8}$, with selected fungi

\begin{tabular}{lccc}
\hline Microorganism & \multicolumn{2}{c}{ Conversion $^{\mathrm{a}, \mathrm{b}}(\%)$} \\
\cline { 2 - 4 } & 6 & 7 & 8 \\
\hline F026 & - & - & - \\
F037 & - & - & - \\
F041 & - & - & - \\
F053 & 11 & 14 & 24 \\
F057 & - & - & - \\
\hline
\end{tabular}

${ }^{a}$ Determined by the area ratio of the product and internal standard area

${ }^{\mathrm{b}}$ Final values after 14 days of reaction
(3), 140 (9), 81 (12), 69 (4), 67 (2), 55 (15). TLC (hexane:dichloromethane, $8: 2 \mathrm{v} / \mathrm{v}$, anisaldehyde stain solution) $R_{f}=0.7$. Spectra: See Fig. S28 in Online Resource 1.

\section{Fungal identification}

\section{Molecular analysis}

DNA extraction was performed following the protocol described by Raeder and Broda (1985). The isolate was screened for ITS loci using the ITS1 and ITS4 primers (White et al. 1990). Amplification reactions were performed using PCR with genomic DNA as a template, and the conditions were set as follows: an initial denaturation temperature of $94{ }^{\circ} \mathrm{C}$ for $2 \mathrm{~min}, 30$ cycles of denaturation at $94^{\circ} \mathrm{C}$ for $1 \mathrm{~min}$, primer annealing at $55{ }^{\circ} \mathrm{C}$ for $1 \mathrm{~min}$, primer extension at $72{ }^{\circ} \mathrm{C}$ for $3 \mathrm{~min}$, and a final extension step at $72{ }^{\circ} \mathrm{C}$ for $3 \mathrm{~min}$ and $4{ }^{\circ} \mathrm{C}$. Amplicons were purified using GFX PCR DNA and a Gel Band Purification Kit (GE Healthcare) and sequenced with BigDye Terminator (Life Technologies, USA) and an ABI3500XL Series Sequencer (Applied Biosystems) according to the manufacturer's instructions. The BioEdit Sequence Alignment Editor v. 7.0.5.3 (Hall 1999) was used to generate the consensus sequence, which was compared against the GenBank nucleotide database (http://www.ncbi.nlm.nih.gov) and CBS (http://www.cbs.knaw.nl/). The most similar sequences were selected, combined with the sequence from the isolate. After alignment using the CLUSTAL X software (Thompson et al. 1994), a phylogenetic tree was generated with MEGA software version 4.0 (Tamura et al. 2007). Neighbor-joining criteria (Saitou and Nei 1987) were used in the analysis, and bootstrap values were calculated for under 1000 pseudoreplicates.

\section{Morphological analysis}

A single-cell preparation was used to ensure the purity of the fungal culture as follows: after a strongly diluted spore suspension was prepared in distilled water, $100 \mu \mathrm{L}$ was transferred to a Neubauer chamber to count the number of colony 


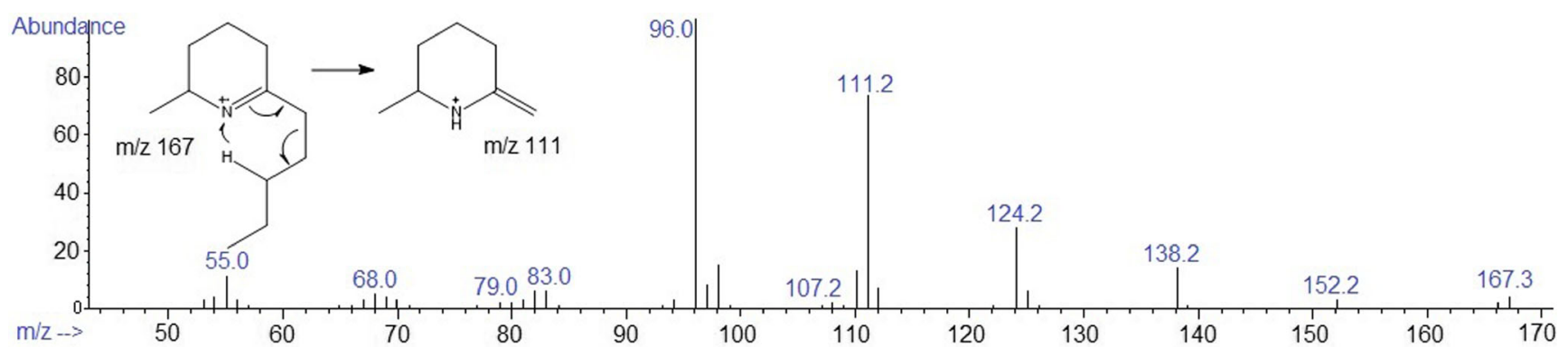

Fig. 4 Mass spectrum EI $(70 \mathrm{eV})$ for $\mathbf{8 a}$

forming units (CFUs). Further dilutions were performed until no more than $5 \mathrm{CFU}$ was found. Then, $100 \mu \mathrm{L}$ of the final diluted suspension was streaked onto a potato dextrose agar (PDA) layer on Petri dishes using a Drigalski spatula. The plates were incubated at $25^{\circ} \mathrm{C}$ until isolated growing colonies were observed. Later, microscopic examination was based on slide preparation by adding a drop of Lactophenol Cotton Blue to a microscope slide and subsequently transferring the fungal material from the culture (Crous et al. 2009).

The ITS sequence of Neopestalotiopsis sp. CBMAI 2030 was deposited at GenBank with accession number KY696576.

\section{Results}

\section{MAO/TA high-throughput screening}

The fluorogenic probe 7-(3-aminopropoxy)coumarin (1) was synthesized in $83 \%$ yield and was successfully applied to the high-throughput screening of 39 fungi in order to quickly select the best strain for TA and/or MAO enzymatic activities (Fig. 1).

The MAO/TA HTS results revealed that 25 fungi catalyzed the oxidative deamination or transamination of probe $\mathbf{1}$ at a relatively low conversion (Table 1 ). On the other hand, the fluorogenic probe was converted into umbelliferone with 30-60\% conversion by five fungi (Table 1): F026, F037, F041, F053, and F057. These microorganisms were selected for further investigation regarding the biotransformation of 2,6-dialkylpiperidines.

\section{Synthesis and biotransformation of 2-methyl-6-alkylpiperidines}

2-Methyl-6-propylpiperidine (6), 2-methyl-6-butylpiperidine (7), and 2-methyl-6-pentylpiperidine (8) were synthesized, as depicted in Fig. 2, aiming at confirming possible MAO activities observed in the HTS experiments.

The synthetic route for $\mathbf{6 , 7}$, and $\mathbf{8}$ (Fig. 3) was based on the synthesis of racemic solenopsins (Pianaro et al. 2012). The

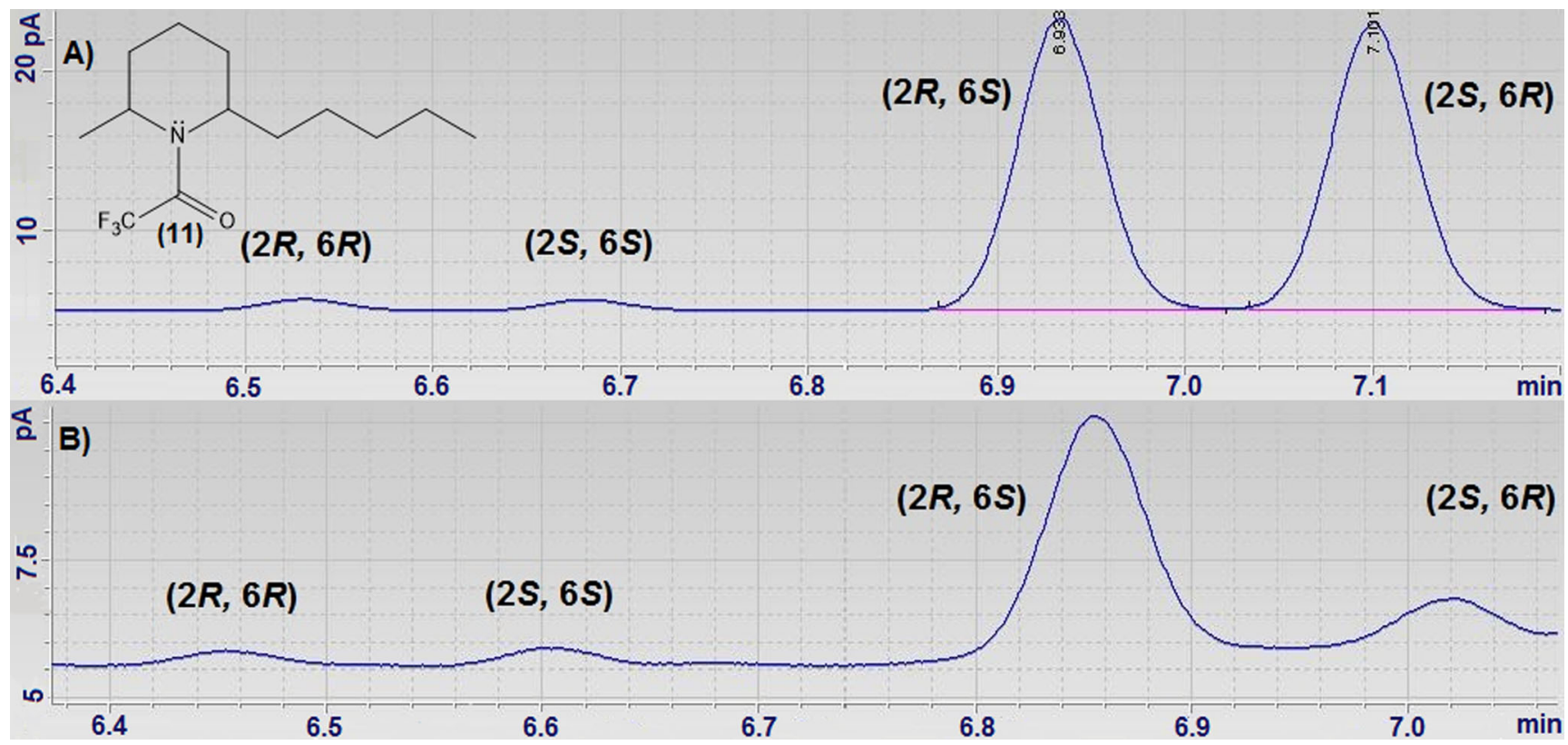

Fig. 5 Chiral GC-FID chromatograms of $\mathbf{1 1}$ a before and $\mathbf{b}$ after biotransformation of $\mathbf{8}$ by fungus F053 (Neopestalotiopsis sp. CBMAI 2030) 
Table 3 Biotransformation of compound $\mathbf{8}$ by Neopestalotiopsis sp. CBMAI 2030

\begin{tabular}{llll}
\hline Microorganism & $\operatorname{Conversion}^{\mathrm{a}, \mathrm{b}}(\%)$ & $e e^{\mathrm{c}}(\%)$ & Selectivity \\
\hline F053 (Neopestalotiopsis sp. CBMAI 2030) & 38 & 73 & $(2 S, 6 R)$ \\
\hline
\end{tabular}

${ }^{a}$ Average using area ratio of product and internal standard

${ }^{\mathrm{b}}$ After 21 days of bioreaction with third-generation cells

${ }^{\mathrm{c}}$ Enantiomeric excess, $e e=((A-B) /(A+B)) \times 100$, where $A$ and $B$ are the areas of the chromatogram peaks of the enantiomers 2,6-lutidin carbanion (10) was obtained by treating lutidine with butyl lithium, which promptly reacted with the appropriate alkyl halide to produce 2-methyl-6-alkylpiridines $\mathbf{6 b}, \mathbf{7 b}$, and $\mathbf{8 b}$. In the second step, the pyridines were hydrogenated in the presence of $10 \% \mathrm{Pt} / \mathrm{C}$ to produce piperidines $\mathbf{6}, \mathbf{7}$, and $\mathbf{8}$. All products and intermediates were fully characterized.

Among the five fungi selected, only F053 showed good MAO activity when tested with $\mathbf{6}, \mathbf{7}$, and $\mathbf{8}$. The remaining microorganisms showed no activity with these piperidines (Table 2).

The piperideines $\mathbf{6 a}, 7 \mathbf{a}$, and $\mathbf{8 a}$ were detected in the reaction media after 7 days with 11,14 , and $24 \%$ conversion, respectively. Using mass spectrometry, 6a, 7a, and $8 \mathbf{a}$ were confirmed, by a characteristic fragment at $m / z 111$ that is rationalized by hydrogen rearrangement through a sixmembered ring intermediate, as in the McLafferty rearrangement (McLafferty and Turecek 1993) (Fig. 4).

Additionally, elongation of the 2-alkyl chain length seems to increase the conversion efficiency of the piperidine into piperideine. Therefore, piperideine 8a formation probably relies on a better acceptance of $\mathbf{8}$ by fungus F053, and this substrate was well suited for the investigation of evolutionary strategies in a laboratory setting, which is usually applied to bacteria with a short generation time. The experimental evolution of Escherichia coli for 40,000 generations in a glucoselimited medium is one of the best-known examples in the field (Bachmann et al. 2012). The present example is the evolution of the F053 fungus toward piperidine 8, and each evolution cycle involved 7 to 15 days. The adaptation lasted three generations to reach a $38 \%$ of $\mathbf{8 a}$. The third generation produced $\mathbf{8 a}$ in higher conversion (38\%) and in shorter time ( 7 days). No further increase was obtained in future generations.

Determination of enantiomeric excess of either $\mathbf{8}$ or $\mathbf{8 a}$ was not an easy task as pure $\mathbf{8}$ or $\mathbf{8 a}$ was not commercially available. The strategy was to use the methodology previously applied by Pianaro et al. (2012) to reveal the absolute configuration of the solenopsins. Racemic cis and trans 8 were trifluoroacetylated (11) and the mixture was analyzed using chiral GC-FID with a $\beta$-cyclodextrin column revealing that 8 was mainly composed of cis isomers. This was confirmed by ${ }^{1} \mathrm{H}$ NMR analyses, with hydrogen $\mathrm{H}-2$ and H-6 chemical shifts as diagnostic (H-6 2.88 ppm and H-2 3.05 ppm) compared to those of the solenopsins (2-methyl-6undecylpiperidines, cis H-6 2.85 ppm and H-2 3.03 ppm, trans
H-6 3.27 ppm and H-2 $3.51 \mathrm{ppm}$ ) (Pianaro et al. 2012). The cis-2-methyl-6-pentylpiperidine isomers $2 R, 6 S$ (6.93 $\mathrm{min})$ and $2 S, 6 R(7.10 \mathrm{~min})$ were eluted after small amounts of trans isomers $2 R, 6 R(6.53 \mathrm{~min})$ and $2 S, 6 S(6.68 \mathrm{~min})$. The chromatographic separation of the trifluoroacetyl derivatives of the 2-methyl-6-pentylpiperidines (11) on the chiral column was similar to Pianaro's et al. (2012) (Fig. 5a). Therefore, analysis of the biotransformation of $\mathbf{8}$ by fungus F053 revealed an enantiomeric excess of $73 \%$ for the cis $(2 S, 6 R)-2$ methyl-6-pentylpiperidine (Fig. 5b and Table 3).

\section{Fungal analysis_-identification}

Molecular analysis of the consensus sequence of the F053 strain indicated that the isolate belongs to the genus Neopestalotiopsis. However, no data enabled identification at the species level. Microscopic observations on PDA culture medium revealed the presence of globosesubglobose pycnidial conidiomatas and discrete conidiogenous cells. Conidia are straight to slightly curved, 4-septate, thin-walled, versicolorous median cells. Hyaline cylindrical apical cells with tubular appendages (branched or not) and basal single, tubular, unbranched appendages were also present. Based on molecular and morphological aspects, the F053 strain was identified as Neopestalotiopsis sp. (Maharachchikumbura et al. 2014).

Neopestalotiopsis commonly occurs as a plant pathogen and together with Pestalotiopsis represents a fungal group known to produce a wide range of chemically novel metabolites (Maharachchikumbura et al. 2014). These species have been recovered from soil, polluted stream water, wood, paper, fabric, and wool (Guba 1961) and are associated with human and animal infections (Sutton 1999).

\section{Discussion}

HTS methods are quick to conduct millions of chemical or pharmacological tests. The results of these experiments provide starting points for the understanding of biochemical processes in biology and for the detection of enzymatic activities (Reetz 2002). Among the available HTS methodologies, those carried out in 96-well microplates with modified substrates (fluorogenic probes) to reveal the enzymatic 
reaction by signals of the fluorophore products are the most common (Reymond 2006). These assays provide quantitative results and can be automated by the use of microplate readers for data acquisition.

Due to its successful application to human MAO-A and MAO-B enzymatic activities ( $\mathrm{Lu}$ et al. 2008), 7-(3aminopropoxy)coumarin (1) was selected as a fluorogenic probe for MAO enzymatic screening in microorganisms, based on our previous experience with whole-cell HTS experiments and analogous probes (Gonçalves and Marsaioli 2014; Lima et al. 2015; Mantovani et al. 2010). In this work, probe 1 was effective on selecting five fungi with possible MAO activity. However, by using this fluorogenic assay, it is not possible to differentiate between MAO and TA activities. As shown in Fig. 1, probe $\mathbf{1}$ produces, either by enzymatic oxidative deamination (MAO) or transamination (TA), the same aldehyde product (3), which undergoes spontaneous $\beta$ elimination releasing the fluorescent umbelliferyl anion (4).

Consequently, in order to overcome this issue, we performed biotransformation experiments using 2-methyl-6alkylpiperidines as substrates to confirm the MAO activities observed in the five fungi selected by HTS. Biotransformation of these compounds must take place only by MAOs, producing the respective piperideines, as TAs do not catalyze reactions involving secondary and tertiary amines.

Using this approach, a monoamine oxidase was confirmed in Neopestalotiopsis sp. CBMAI 2030 (isolate F053), which transformed all evaluated piperidines and, on its best, deracemized 2-methyl-6-pentylpiperidine into $(2 R, 6 S)-2$ methyl-6-pentylpiperidine in $38 \%$ conversion and $73 \%$ ee within 7 days. The piperideine enantiomeric excess was not accessed due to a lack of standards and enantiomeric discrimination methods. These results also attested the efficiency of probe 1 and the HTS technique in detecting new MAOs.

For years, 2-methyl-6-alkylpiperidines are the subject of research in our group. These alkaloids are also known as solenopsins because they are the main constituents of Solenopsis ant venom. The two stereocenters of the solenopsins allow the existence of four stereoisomers: trans $(2 R, 6 R$ or $2 S, 6 S)$ and cis $(2 R, 6 S$ or $2 S, 6 R)$, and the ratio of these diastereoisomers in the venom composition varies between Solenopsis worker ants and queens (Pianaro et al. 2012).

Concerning biocatalytic synthesis, Reilly et al. (2014) developed a chemo-enzymatic process for the production of chiral 2,5-disubstituted pyrrolidines using transaminase and monoamine oxidase from $A$. niger (MAO-N), obtaining excellent enantioselectivity and diastereoselectivity. With the activity showed by Neopestalotiopsis sp. CBMAI 2030, this chemo-enzymatic process could be applied to give access to enantiomerically pure 2,6-disubstituted piperidines (solenopsins), shading light into the role of the absolute configuration and the ant communication inside the nests.
Fungal monoamine oxidase from $A$. niger and its variants are the main monoamine oxidases used as biocatalyst for the deracemization of secondary and tertiary amines (Carr et al. 2005; Dunsmore et al. 2006). The wild-type MAO-N is most active on simple straight-chain amines and shows poor activity with cyclic amines, which demanded several rounds of direct evolution to enhance its substrate acceptance (Carr et al. 2003). This characteristic creates the opportunity to search for new wild-type MAOs with distinct activity scope. Therefore, this report adds a new enzyme to the known MAO panel and the gene and heterologous expression of this novel MAO is under investigation.

Acknowledgements The authors are indebted to FAPESP (São Paulo Research Foundation, Grant 2010/51278-0 and BZC scholarship 2014/22967-3), CNPq (National Council for Scientific and Technological Development, Grant 307885/2013-5), and CAPES (Coordination for the Improvement of Higher Education Personnel, JHC scholarship) for their financial support. We wish to thank Prof. Fernando Antonio Santos Coelho (IQ/UNICAMP) for the use of the hydrogenator apparatus.

\section{Compliance with ethical standards}

Funding This study was funded by FAPESP (Grant 2010/51278-0 and BZC scholarship 2014/22967-3), CNPq (Grant 307885/2013-5), and CAPES (JHC scholarship).

Conflict of interest The authors declare that they have no conflict of interest.

Ethical approval This article does not contain any studies with human participants performed by any of the authors.

Open Access This article is distributed under the terms of the Creative Commons Attribution 4.0 International License (http:// creativecommons.org/licenses/by/4.0/), which permits unrestricted use, distribution, and reproduction in any medium, provided you give appropriate credit to the original author(s) and the source, provide a link to the Creative Commons license, and indicate if changes were made.

\section{References}

Atkin KE, Reiss R, Koehler V, Bailey KR, Hart S, Turkenburg JP, Turner NJ, Brzozowski AM, Grogan G (2008a) The structure of monoamine oxidase from Aspergillus niger provides a molecular context for improvements in activity obtained by directed evolution. J Mol Biol 384(5):1218-1231. doi:10.1016/j.jmb.2008.09.090

Atkin KE, Reiss R, Turner NJ, Brzozowskia AM, Grogan G (2008b) Cloning, expression, purification, crystallization and preliminary X-ray diffraction analysis of variants of monoamine oxidase from Aspergillus niger. Acta Cryst 64(Pt 3):182-185. doi:10.1107/ S174430910800345X

Bachmann H, Kleerebezem M, Starrenburg MJC, Molenaar D, Vlieg JETH (2012) Microbial domestication signatures of Lactoccus lactis can be reproduced by experimental evolution. Genome Res 22(1): 115-124. doi:10.1101/gr.121285.111

Bicalho B, Chen LS, Grognux J, Reymond J-L, Marsaioli AJ (2004) Studies on whole cell fluorescence-based screening for epoxide 
hydrolases and Baeyer-Villiger monoxygenases. J Braz Chem Soc 15(6):911-916. doi:10.1590/S0103-50532004000600019

Carr R, Alexeeva M, Enright A, Eve TSC, Dawson MJ, Turner NJ (2003) Directed evolution of an amine oxidase possessing both broad substrate specificity and high enantioselectivity. Angew Chem Int Ed Engl 42(39):4807-4810. doi:10.1002/anie.200352100

Carr R, Alexeeva M, Dawson MJ, Gotor-Fernandez V, Humphrey CE, Turner NJ (2005) Directed evolution of an amine oxidase for the preparative deracemisation of cyclic secondary amines. Chembiochem 6:637-639. doi:10.1002/cbic.200400329

Crous PW, Verkley GJM, Groenewald JZ, Samson RA (2009) Fungal biodiversity-CBS Laboratory Manual Series. CBS-KNAW Fungal Diversity Centre, Utrecht, ISSN 1879-6877, p 269

Dunsmore CJ, Carr R, Fleming T, Tuner NJ (2006) A chemoenzymatic route to enantiomerically pure cyclic tertiary amines. J Am Chem Soc 128(7):2224-2225. doi:10.1021/ja058536d

France SP, Hussain S, Hill AM, Hepworth LJ, Howard RM, Mulholland KR, Flitsch SL, Turner NJ (2016) One-pot cascade synthesis of mono- and disubstituted piperidines and pyrrolidines using carboxylic acid reductase (CAR), $\omega$-transaminase ( $\omega$-TA), and imine reductase (IRED) biocatalysts. ACS Catal 6:3753-3759. doi:10.1021/ acscatal.6b00855

Gonçalves CCS, Marsaioli AJ (2014) Monitoring enzymatic activities with fluorogenic probes. Quim Nov. 37:1028-1036. doi:10.5935/ 0100-4042.20140142

Guba EF (1961) Monograph of Pestalotia and Monochaetia. Harvard University Press, Cambridge

Hall TA (1999) BioEdit: a user-friendly biological sequence alignment editor and analysis program for Windows 95/98/ NT. Nucleic Acids Symp Ser 41:95-98

Hwang BY, Kim BG (2004) High-throughput screening method for the identification of active and enantioselective $\omega$-transaminases. Enzym Microb Technol 34:429-436. doi:10.1016/j.enzmictec. 2003.11.019

Koszelewski D, Tauber K, Faber K, Kroutil W (2010) $\omega$-Transaminases for the synthesis of non-racemic $\alpha$-chiral primary amines. Trends Biotechnol 28:324-332. doi:10.1016/j.tibtech.2010.03.003

Leclercq S, Braekman JC, Daloze D (1996) Biosynthesis of the solenopsins, venom alkaloids of the fire ants. Naturwissenschaften $53: 222-225$

Lima MLSO, Gonçalves CCS, Barreiro JC, Cass QB, Marsaioli AJ (2015) High throughput enzymatic enantiomeric excess: quick-ee. J Braz Chem Soc 26:319-324. doi:10.5935/0103-5053.20140282

Lu YY, Wang YG, Dai B, Dai YQ, Wang Z, Fu ZW, Zhu Q (2008) A novel fluorogenic probe for monoamine oxidase assays. Chin Chem Lett 19:947-950. doi: 10.1016/j.cclet.2008.05.032

Maharachchikumbura SSN, Hyde KD, Groenewald JZ, Xu J, Crous PW (2014) Pestalotiopsis revisited. Stud Mycol 79:121-186. doi:10. 1016/j.simyco.2014.09.005
Mantovani SM, Oliveira LG, Marsaioli AJ (2010) Esterase screening using whole cells of Brazilian soil microorganisms. J Braz Chem Soc 21:1484-1489. doi:10.1590/S0103-50532010000800011

McLafferty FW, Turecek F (1993) Interpretation of mass spectra, 4th edn. University Science Books, Mill Valley

Perrin DD, Armarego WLF, Perrin DR (1980) Purification of laboratory chemicals, 2nd edn. Oxford, Pergamon Press

Pianaro A, Fox EGP, Bueno OC, Marsaioli AJ (2012) Rapid configuration analysis of the solenopsins. Tetrahedron Asymmetry 23:635642. doi:10.1016/j.tetasy.2012.05.005

Raeder J, Broda P (1985) Rapid preparation of DNA from filamentous fungi. Lett Appl Microbiol 1:7-20. doi:10.1111/j.1472-765X.1985. tb01479.x

Reetz MT (2002) New methods for the high-throughput screening of enantioselective catalysts and biocatalysts. Angew Chem Int Edit 41:1335-1338. doi:10.1002/1521-3773(20020415)41:8<1335:: AID-ANIE1335>3.0.CO;2-A

Reilly RO, Iglesias C, Ghislieri D, Hopwood J, Galman JL, Lloyd RC, Turner NJ (2014) A regio- and stereoselective $\omega$-transaminase/ monoamine oxidase cascade for the synthesis of chiral 2,5-disubstituted pyrrolidines. Angew Chem Int Ed Engl 53:2447-2450. doi:10. 1002/anie.201309208

Reymond J-L (2006) Enzyme assays: high-throughput screening, genetic selection and fingerprinting. Wiley, Weinheim, p 368

Reymond J-L (2008) Substrate arrays for fluorescence-based enzyme fingerprinting and high-throughput screening. Ann N Y Acad Sci 1130:12-20. doi:10.1196/annals. 1430.000

Saitou N, Nei M (1987) The neighbor-joining method: a new method for reconstructing phylogenetic trees. Mol Biol Evol 4(4):406-425

Sørensen SPL (1909) Enzymstudien. II. Mitteilung. Über die Messung und die Bedeutung der Wasserstoffionenkoncentration bei enzymatischen Prozessen. Biochem Z 21:131-304

Sutton DA (1999) Coelomycetous fungi in human disease. A review: clinical entities, pathogenesis, identification and therapy. Rev Iberoam Micol 16(4):171-179

Tamura K, Dudley J, Nei M, Kumar S (2007) MEGA4: Molecular Evolutionary Genetics Analysis (MEGA) software version 4.0. Mol Biol Evol 24(80):1596-1599. doi:10.1093/molbev/msm092

Thompson JD, Higgins DG, Gibson TJ (1994) Clustal W: improving the sensitivity of progressive multiple alignment through sequence weighting, positions-specific gap penalties and weight matrix choice. Nucleic Acids Res 22:4673-4680

White TJ, Bruns TD, Lee SB, Taylor JW (1990) Amplification and direct sequencing of fungal ribosomal RNA genes for phylogenetics. PCR protocols: a guide to methods and applications. Academic Press, Inc., New York, pp 315-322 